\title{
Electrophoretic Variation in Human Serum Ceruloplasmin: A New Genetic Polymorphism
}

\author{
D. C. Shreffler, ${ }^{1}$ G. J. Brewer, ${ }^{1,2}$ J. C. Gall, ${ }^{1,2}$ and M. S. Honeyman ${ }^{3}$
}

Received 27 March 1967-Final 18 May 1967

Through the application of a specific oxidase stain to results of starch gel electrophoresis of human serum, three different electrophoretic forms of ceruloplasmin-denoted $C p A$ (fast), $C p B$ (intermediate), and $C p C$ (slow)-have been defined. The electrophoretic differences are small and were first recognized through a rare variant individual who had only the fast and slow forms. Five phenotypes displaying different combinations of the three electrophoretic forms have been defined in American Negroes; these are called $C p A, C p A B, C p B, C p A C$, and $C p B C$. Twin, family, and population studies have yielded evidence indicating that the $A$ and $B$ electrophoretic forms are controlled by $a$ pair of autosomal codominant alleles, designated $\mathrm{Cp}^{\mathrm{A}}$ and $\mathrm{Cp}^{\mathrm{B}}$, and suggesting that the $C$ form may be determined by a third allele, $\mathrm{Cp}^{\mathrm{C}}$, at the same locus. The variants constitute a genetic polymorphism in American Negroes, but occur only rarely in Caucasians.

\section{INTRODUCTION}

Ceruloplasmin is a copper-containing, serum $\alpha_{2}$-globulin first described by Holmberg and Laurell (1948). It has oxidase activity for a number of naturally occurring compounds, such as dopa, epinephrine, and serotonin ( $c$. Laurell, 1960), but exhibits greatest activity against $p$-phenylenediamine and $o$-dianisidine. The biological function of ceruloplasmin is unknown; it may play a role in copper metabolism or as an oxidative enzyme, but this remains to be clarified ( $c f$. Laurell, 1960; Bearn, 1966). It is of clinical interest because of the striking reduction of its concentration in

Supported by U.S. Atomic Energy Commission Contract AT(11-1)-1552, by U.S. Public Health Service Research Grants AM 09381 and HD 02083, and by U.S. Public Health Service Career Development Awards 6-K3-HE-24, 980 (DCS) and 1-K3-A-7959 (GJB).

${ }^{1}$ Department of Human Genetics, University of Michigan, Ann Arbor, Michigan.

2 Department of Medicine (Simpson Memorial Institute), University of Michigan, Ann Arbor, Michigan.

${ }^{3}$ Connecticut State Department of Health, Hartford, Connecticut. 
Wilson's disease ( $c f$. Bearn, 1966) and the increase in concentration resulting from infections, fever, administration of certain hormones, pregnancy, certain malignancies, and immunizations ( $c f$. Laurell, 1960). Genetically determined structural variation in this protein has heretofore appeared infrequent. Martin et al. (1961) reported the only documented case of genetic variation in man, a single rapidly migrating electrophoretic form of ceruloplasmin, called $\mathrm{Cp} 1 \mathrm{~F}$, which was transmitted in a dominant inheritance pattern through four generations of one family. No further examples of this variant were found, however, among an additional 250 sera surveyed. Imlah (1964) observed a genetically determined, rapidly migrating electrophoretic variant of ceruloplasmin in swine.

A number of workers have pointed out the electrophoretic heterogeneity of purified ceruloplasmin (Broman, 1958; Morell and Scheinberg, 1960; Richterich et al., 1962; Poulik and Bearn, 1962), and it was suggested that the minor electrophoretic bands occurring in ceruloplasmin purified from pooled human serum might result from genetic polymorphism among the donors who contributed to the pool (Morell and Scheinberg, 1960). However, further studies indicated that a more probable source of this heterogeneity was polymerization or denaturation of the highly concentrated, purified material (Poulik and Bearn, 1962; Poulik, 1963).

Owen and Smith (1961) reported that o-dianisidine, a compound used as a substrate for detection of hemoglobin-haptoglobin complexes on starch gels by their peroxidase activity, was also oxidized by ceruloplasmin in the absence of peroxide. These authors described a staining procedure which permitted staining for both ceruloplasmin and haptoglobin on the same starch gel. This staining procedure has been used routinely for typing of serum haptoglobin and ceruloplasmin in our laboratory.

After several years of application of this method, electrophoretic polymorphism in ceruloplasmin was detected among Negro sera. However, the electrophoretic differences which occur are so small that they initially went undetected. They became apparent only after discovery of one individual with two electrophoretic variantsone faster than normal, the other slower than normal. Upon examination of sera from the family of the proposita using modified electrophoretic conditions, the polymorphism became apparent. This paper presents the details of the detection, resolution, genetic control, and distribution of these electrophoretic variants. A preliminary report of these findings has previously been published (Shreffler et al., 1966).

\section{MATERIALS AND METHODS}

\section{Serum and Plasma Specimens}

Samples from 86 pairs of Negro female twins collected in Connecticut, Georgia, and Chicago, Illinois, were available from a study on quantitative variation in expression of glucose 6-phosphate dehydrogenase (G 6-PD) deficiency in heterozygotes (Brewer et al.; 1967). Methods for determination of zygosity of these twins are described in the previous paper. In many instances, one or both parents and the siblings of twins 
were also sampled, and many families were obtained from this material for genetic studies. Additional Negro family groups, collected in Georgia and South Carolina, were available from a further study of G 6-PD quantitative variation presently in progress. A random series of 374 sera was obtained from a group of male Negro prisoners who were volunteers in another investigation. A sample of 334 Caucasian specimens was drawn from a group of sera collected from a long-term epidemiological survey of an entire town, the Tecumseh (Michigan) Community Health Study (Epstein, 1960). Most of the specimens described above were plasmas collected in acid-citrate-dextrose solution. A few were heparinized plasmas, and some were serum from clotted blood. All three types of specimens gave entirely consistent results. However, it was found that plasmas collected in EDTA could not be classified because of inhibition by the EDTA of ceruloplasmin oxidase activity.

\section{Electrophoretic Conditions}

Horizontal starch gel electrophoresis was carried out essentially as described by Smithies (1955). For optimal ceruloplasmin resolution, $11.8 \mathrm{~g}$ hydrolyzed starch (Connaught Medical Laboratories, lot 245) was used per $100 \mathrm{ml}$ borate gel buffer $(0.016 \mathrm{M}$ boric acid, $0.010 \mathrm{M}$ sodium hydroxide, $p \mathrm{H} 9.5)$. The cell buffer was $0.21 \mathrm{M}$ boric acid, $0.085 \mathrm{M}$ sodium hydroxide, $p \mathrm{H}$ 9.0. Electrophoresis was carried out at $4 \mathrm{C}$ for $22 \mathrm{hr}$ at $7 \mathrm{v} / \mathrm{cm}$. Serum samples were routinely diluted one-third before electrophoresis to reduce the intensity of ceruloplasmin staining and enhance discrimination among the electrophoretic variants.

Immunoelectrophoresis was carried out on $8 \times 10 \mathrm{~cm}$ glass slides with No. 2 Ionagar (Consolidated Laboratories) as the supporting medium. The buffer system and electrophoretic conditions were those described by Hirschfeld (1959). Specific rabbit anticeruloplasmin serum was obtained commercially (Hyland Laboratories, Los Angeles).

\section{Staining}

Ceruloplasmin was localized after electrophoresis by a slight modification of the method of Owen and Smith (1961). The gel slices were incubated in a solution of $0.1 \% o$-dianisidine (Nutritional Biochemicals) and 20\% ethanol in $0.04 \mathrm{~m}$ acetate buffer, $p H$ 5.5. After incubation in this solution for approximately $1 \mathrm{hr}$ at $37 \mathrm{C}$, the ceruloplasmin bands were clearly apparent and sharply defined, when examined over an X-ray film illuminator. At this point, ceruloplasmin type was classified and the gels were photographed on Panatomic-X film with transmitted light. Photography. was necessary because upon storage the ceruloplasmin zones continue to increase in intensity and to broaden and diffuse, so that by 12-24 hr after staining the electrophoretic variants are obscured or at best poorly distinguishable. When desired, the gel was subsequently stained for haptoglobin by adding to the ceruloplasmin staining solution one-half volume of $0.1 \mathrm{M}$ acetate buffer $(p \mathrm{H} \mathrm{4.7)}$ and 0.02 volume of $3 \%$ hydrogen peroxide. The hemoglobin-haptoglobin zones developed in 5-10 min at room temperature. 


\section{RESULTS}

\section{Detection of Electrophoretic Variation}

Prior to the studies reported here, approximately 9000 Caucasian sera, 500 American Indian sera, and 1000 Negro sera had been classified in our laboratory for haptoglobin type using the ceruloplasmin-haptoglobin staining procedure, without detection of significant variation in the ceruloplasmins. The electrophoretic procedure used for these classifications differed from that described in the preceding section only in that the sera were undiluted and electrophoresis was carried out for only $16 \mathrm{hr}$ at $6 \mathrm{v} / \mathrm{cm}$. The existence of ceruloplasmin variation became apparent when, upon routine screening, serum from the mother of one of the twin pairs showed two distinct ceruloplasmin bands. Figure 1 shows this result. Note that the other two specimens on this starch gel show only a single ceruloplasmin band and that neither of the two bands of the proposita's serum seems to match in mobility the band of the adjacent sera. A second specimen from the proposita gave a similar result. Analysis of sera from several members of the proposita's family under the same electrophoretic conditions gave the result shown in Fig. 2. Note the indication of slight mobility differences among these sera. When these same sera were diluted and subjected to electrophoresis as described for optimal ceruloplasmin resolution, the result shown in Fig. 3 was obtained.

It is apparent in Fig. 3 that five distinct phenotypes occur in this family. The single electrophoretic species occurring in the most frequent phenotype (shown in positions 1 and 6 ) may also occur in combination with a faster electrophoretic form (position 2) or a slower electrophoretic form (position 5). The proposita's serum. (position 4) lacks the usual band and has instead the fast and the slow bands. The fifth phenotype (position 3 ) has only the fast electrophoretic form. These phenotypes have been given the designations $\mathrm{CpB}, \mathrm{CpAB}, \mathrm{CpA}, \mathrm{CpAC}$, and $\mathrm{CpBC}$, with the $\mathrm{A}$ electrophoretic species being the fastest form, $B$ the common, intermediate form, and $\mathrm{C}$ the slow form.

\section{Proposed Mode of Inheritance}

The pedigree of the proposita's family is shown in Fig. 4, and with one exception the pedigree is consistent with genetic control of the ceruloplasmin differences by three codominant alleles at an autosomal locus. The $\mathrm{CpB}$ phenotype would appear to correspond to the homozygote for a common $C p^{B}$ allele, the $\mathrm{CpA}$ phenotype to the homozygote for a $C p^{A}$ allele, and the $\mathrm{CpAB}, \mathrm{CpBC}$, and $\mathrm{CpAC}$ types to the heterozygous genotypes, $C p^{A} / C p^{B}, C p^{B} / C p^{C}$, and $C p^{A} / C p^{C}$, respectively. As shown in Fig. 4, the proposita (II-12) has apparently transmitted $C p^{C}$ to her three children. The father(s) of these children was not available for study; it is assumed that he had at least one $C p^{B}$ gene. The proposita presumably received $C p^{A}$ from her mother (I-2), a $\mathrm{CpAB}$, but the origin of the postulated $C p^{C}$ gene of the proposita is unknown. She is excluded as a child of I-3 on the basis of haptoglobin type, and the identity of her true father is uncertain. Her mother, according to the hypothesis, has transmitted $C p^{A}$ to six of her children and $C p^{B}$ to five. The mother's child, II-5, of presumed 


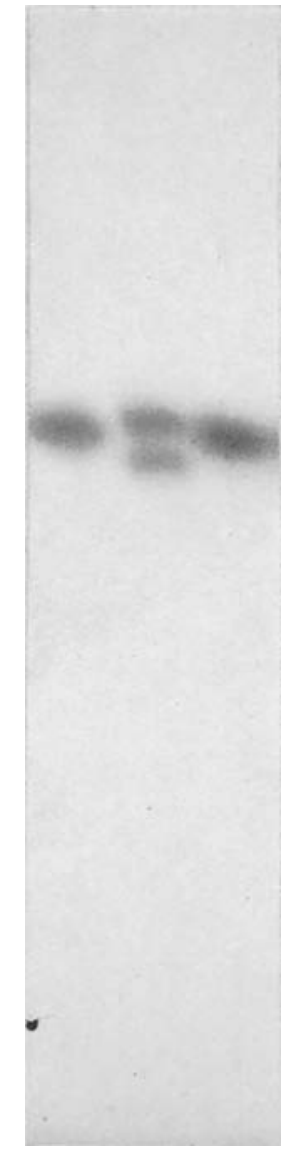

Fig. 1. Ceruloplasmin patterns of three sera after electrophoresis on starch gel for $16 \mathrm{hr}$ at $6 \mathrm{v} / \mathrm{cm}$. The anode was at the top of the figure. The proposita's serum was in the center; the other two samples were random Negro sera. 


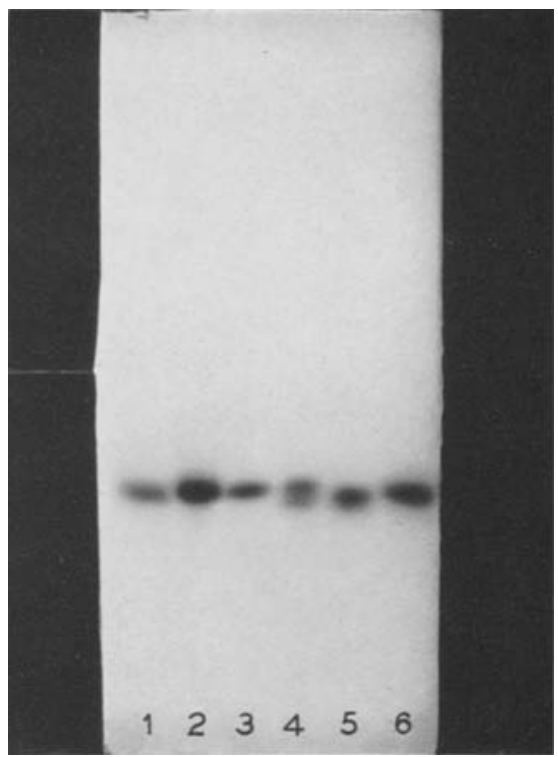

Fig. 2. Ceruloplasmin patterns of sera from the proposita (no. 4) and five members of her family after electrophoresis on starch gel for $16 \mathrm{hr}$ at $6 \mathrm{v} / \mathrm{cm}$. The anode was at the top.

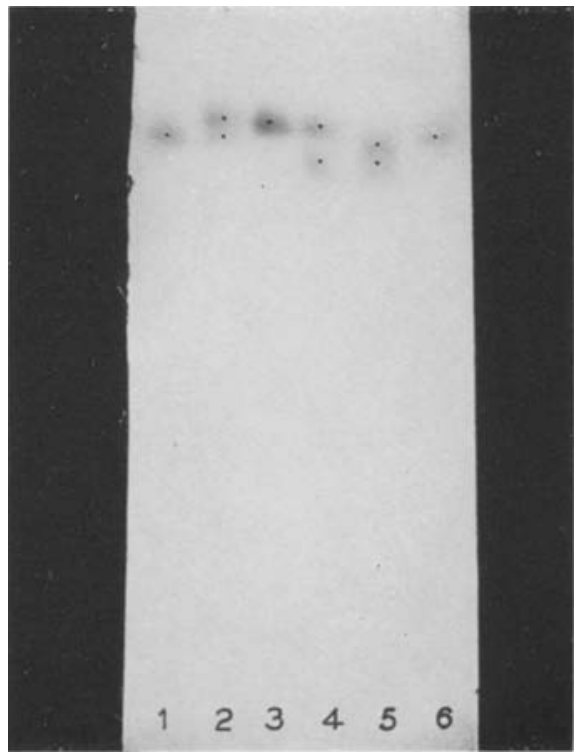

Fig. 3. Ceruloplasmin patterns of the same sera shown in Fig. 2 after electrophoresis of the sera, at one-third dilution, for $22 \mathrm{hr}$ at $7 \mathrm{v} / \mathrm{cm}$. The anode was at the top. The five phenotypes shown are (1) $\mathrm{CpB}$; (2) $\mathrm{CpAB}$; (3) $\mathrm{CpA}$; (4) $\mathrm{CpAC}$; (5) $\mathrm{CpBC}$; (6) $\mathrm{CpB}$. 
genotype $C p^{A} / C p^{A}$, constitutes an exception to the postulated mode of inheritance in that his supposed father ( $\mathrm{I}-1)$ is $\mathrm{CpB}$ and could not have transmitted $C p^{A}$. This child is not excluded on the basis of other genetic systems; however, only 4 of the 11 systems classified offered the opportunity for detection of exclusion, so the possibility of illegitimacy should certainly be entertained. Note transmission of $C p^{A}$ from male II-7 to his sons III- 1 and III-4, excluding any sex-linked effect.

Further evidence supporting the existence of the $C p^{A}$ and $C p^{B}$ alleles is presented in a later section. A sixth phenotype, $\mathrm{CpC}$, which would be predicted by the threeallele hypothesis (genotype $C p^{C} / C p^{C}$ ), is not seen in Fig. 4 and has not thus far been detected elsewhere, but is expected to be very rare. It should be pointed out that the only present evidence for allelism of the gene determining the $\mathrm{C}$ electrophoretic form

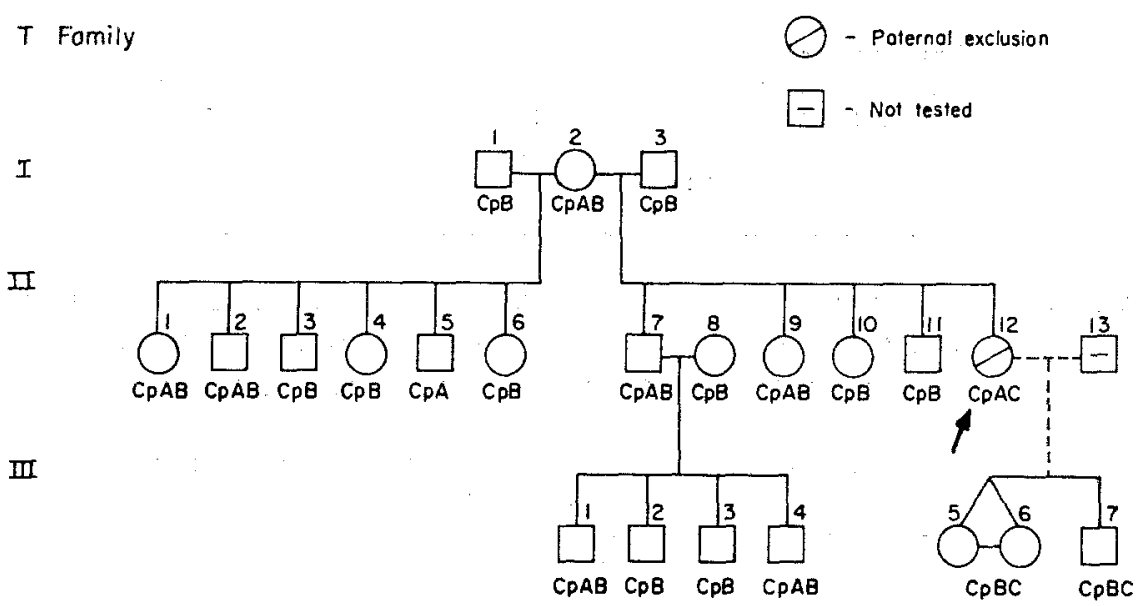

Fig. 4. Pedigree of the proposita's family. The proposita was female II-12.

with $C p^{A}$ and $C p^{B}$ is the existence of the $C \mathrm{pAC}$ phenotype. If the $C$ electrophoretic difference were determined by a different locus from the A type, then, in a double heterozygote, one would expect to find the B electrophoretic form as well.

\section{Twin Data}

Since it had been shown previously that ceruloplasmin is somewhat unstable and tends to form altered electrophoretic species as artifacts of the native forms, it could be argued that the observations in the $T$ family were due to nongenetic factors in their environment, or to artifacts introduced in the collection and handling of the blood specimens, which were all obtained at the same time. As a test of such an effect, a series of specimens from twins was examined. With few exceptions, the samples from both cotwins in this series were also collected at the same time and handled in the same way. The twin data are shown in Table I. All of the monozygotic twins are concordant, including four pairs which have variant types. Among the dizygotic pairs, two are concordant for variant phenotypes and six are discordant. These 
results strengthen the assumption that the observed electrophoretic variation is genetically determined.

\section{Segregation Data}

To test further the suggested mode of inheritance, all available Negro family groups were surveyed. The segregation data for 114 families are summarized in Table II.

Table I. Ceruloplasmin Types of Negro Twin Pairs

\begin{tabular}{lcccccc}
\hline $\begin{array}{c}\text { Monozygotic twins } \\
\text { Concordant for: } \\
\text { Number of pairs: }\end{array}$ & B & AB & A & BC & Total \\
$\begin{array}{c}\text { Discordant for: } \\
\text { None }\end{array}$ & & & & & 40 \\
$\begin{array}{c}\text { Dizygotic twins } \\
\text { Concordant for: } \\
\quad \text { Number of pairs: }\end{array}$ & B & AB & A & BC & $\begin{array}{c}\text { Total } \\
40\end{array}$ \\
$\begin{array}{c}\text { Discordant for: } \\
\text { Number of pairs: }\end{array}$ & $1-\mathrm{B}$, & $1-\mathrm{AB}$ & & & $\begin{array}{c}\text { Total } \\
6\end{array}$ \\
\hline
\end{tabular}

Since, as will be shown in the following section, only about $10 \%$ of Negroes are $\mathrm{CpAB}$, and less than $1 \%$ are $\mathrm{CpA}$ and $\mathrm{CpBC}$, the only extensive data which could be obtained were on the most frequent three mating types- $\mathrm{CpB} \times \mathrm{CpB}$ (in all mating

Table II. Segregation of Ceruloplasmin Types Among Offspring from Several Mating Types

\begin{tabular}{cccccc}
\hline & & \multicolumn{5}{c}{ Number of offspring } \\
\cline { 5 - 7 } Mating type $^{a}$ & $\begin{array}{c}\text { Number of } \\
\text { families }\end{array}$ & $\mathrm{CpA}$ & $\mathrm{CpAB}$ & $\mathrm{CpB}$ & $\mathrm{CpBC}$ \\
\hline $\mathrm{B} \times \mathrm{B}$ & 40 & 0 & 0 & 118 & 0 \\
$\mathrm{AB} \times \mathrm{B}$ & 8 & 1 & 18 & 14 & 0 \\
$\mathrm{~B} \times \mathrm{AB}$ & 7 & 0 & 12 & 15 & 0 \\
$\mathrm{AB} \times \mathrm{AB}$ & 2 & 1 & 3 & 3 & 0 \\
$\mathrm{BC} \times \mathrm{B}$ & 1 & 0 & 0 & 3 & 0 \\
$\mathrm{~B} \times ?$ & 41 & $0(0)^{b}$ & $5(4.5)^{b}$ & $78(79.3)^{b}$ & $1(0.3)^{b}$ \\
$? \times \mathrm{B}$ & 9 & $0(0)^{b}$ & $2(0.7)^{b}$ & $12(13.2)^{b}$ & $0(0.1)^{b}$ \\
$\mathrm{AB} \times ?$ & 4 & $0(0.4)^{b}$ & $8(8.0)^{b}$ & $8(7.6)^{b}$ & $0(0)^{b}$ \\
$\mathrm{AC} \times ?$ & 1 & 0 & 0 & 0 & 2 \\
$\mathrm{BC} \times ?$ & 1 & 0 & 0 & 1 & 0 \\
& & & & & \\
\hline
\end{tabular}

a Mother's phenotype $\times$ father's phenotype.

${ }^{b}$ Expectations calculated on the basis of the gene frequencies in Table III.

types discussed herein, the female parent is given first), $\mathrm{CpAB} \times \mathrm{CpB}$, and $\mathrm{CpB} \times \mathrm{CpAB}$. However, two $\mathrm{CpAB} \times \mathrm{CpAB}$ matings and one $\mathrm{CpBC} \times \mathrm{CpB}$ mating were found. In addition, a large amount of information was available from families in which only one parent was typed. The other parent in these cases was unavailable, excluded by blood group data, or not sampled because he was not required for the investigations 
for which the specimens were originally collected. These single-parent offspring groups also provide information with regard to the mode of inheritance and are included in Table II. With the exception of the single $\mathrm{CpA}$ from the $\mathrm{CpAB} \times \mathrm{CpB}$ mating previously noted (individual II-5 in Fig. 4), all of the segregation data are consistent with genetic control of the $\mathrm{A}$ and $\mathrm{B}$ electrophoretic forms of ceruloplasmin by a pair of codominant alleles at an autosomal locus. The $\mathrm{CpB} \times \mathrm{CpB}$ matings yield only $\mathrm{CpB}$ offspring, the $\mathrm{CpAB} \times \mathrm{CpB}$ and $\mathrm{CpB} \times \mathrm{CpAB}$ matings produce the expected equal numbers of $\mathrm{CpB}$ and $\mathrm{CpAB}$, and the $\mathrm{CpAB} \times \mathrm{CpAB}$ matings produce the expected three phenotypes. The fact that the segregation ratio is the same in the $\mathrm{CpAB} \times \mathrm{CpB}$ and $\mathrm{CpB} \times \mathrm{CpAB}$ matings argues against any effect of sex, as does the fact that in the $\mathrm{CpB} \times \mathrm{CpAB}$ matings six of the twelve $\mathrm{CpAB}$ offspring were males. The data from families in which only a single parent was available are also consistent with the postulated mode of inheritance. The expectations for the offspring of $\mathrm{CpB} \times$

Table III. Distribution of Ceruloplasmin Phenotypes by Sex Among Unrelated American Negroes and Caucasians

\begin{tabular}{|c|c|c|c|c|c|c|}
\hline \multirow[b]{2}{*}{ Population } & \multirow[b]{2}{*}{ Sex } & \multicolumn{5}{|c|}{ Number of phenotype } \\
\hline & & $\mathrm{CpA}$ & CpAB & $\mathrm{CpB}$ & $\mathrm{CpAC}$ & $\mathrm{CpBC}$ \\
\hline \multirow[t]{3}{*}{ American Negro } & Male & 1 & 46 & 391 & 0 & 2 \\
\hline & Female & 1 & 10 & 123 & 1 & 1 \\
\hline & Total & $\overline{2}(1.6)^{a}$ & $56(57.6)$ & $\overline{514}(513.3)$ & $\overline{1}(0.2)$ & $\overline{3}(3.3)$ \\
\hline \multirow[t]{3}{*}{ American Caucasian } & Male & 0 & 3 & 153 & 0 & 0 \\
\hline & Female & 0 & 1 & 177 & 0 & 0 \\
\hline & Total & $\overline{0}$ & $\overline{4}$ & $\overline{330}$ & $\overline{0}$ & $\overline{0}$ \\
\hline Gene frequencies: & $\begin{array}{l}\text { Negroes } \\
\text { Caucasians }\end{array}$ & $\begin{array}{l}C p^{A}=0.053 \\
C p^{A}=0.006\end{array}$ & \multicolumn{2}{|c|}{$\begin{array}{l}C p^{B}=0.944 \\
C p^{B}=0.994\end{array}$} & $=0.003$ & \\
\hline
\end{tabular}

${ }^{a}$ The numbers in parentheses are expectations under Hardy-Weinberg equilibrium.

$\mathrm{Cp}$ ?, $\mathrm{Cp} ? \times \mathrm{CpB}$, and $\mathrm{CpAB} \times \mathrm{Cp}$ ? matings were based upon the $C p^{A}, C p^{B}$, and $C p^{C}$ gene frequency estimations for American Negroes presented in the next section.

The segregation data strongly support the existence of a pair of autosomal codominant alleles, $C p^{A}$ and $C p^{B}$, determining the $\mathrm{A}$ and $\mathrm{B}$ electrophoretic forms. In view of the paucity of data on the $\mathrm{CpAB} \times \mathrm{CpAB}$ mating, the lack of data on other mating types, and the one exception in the $\mathrm{CpAB} \times \mathrm{CpB}$ mating, additional data will be necessary to confirm this rigorously, but at this point it would appear justified to conclude that the mode of inheritance postulated is the correct one. No critical genetic data have thus far been obtained concerning the relationship of the determinant of the $C p C$ electrophoretic form to $C p^{A}$ and $C p^{B}$, and the families in which $\mathrm{CpC}$ occurred (Table II) are not particularly informative with regard to the mode of inheritance of this variant, so a final decision on genetic control of $\mathrm{CpC}$ must await further evidence. Pending further data, based upon the occurrence of the $\mathrm{CpAC}$ 
phenotype, we will provisionally designate a $C p^{C}$ allele, codominant with $C p^{A}$ and $C p^{B}$, for control of the slow electrophoretic form.

\section{Population Distribution}

The results of a survey of unrelated Negroes (including the prisoner series and all unrelated individuals from the family material) and of unrelated Caucasians (Tecumseh material) are presented by race and sex in Table III. There is no sex difference in the distributions. Although there is a somewhat higher frequency of $\mathrm{CpAB}$ among Negro males, the difference is not significant. The CpA type is clearly polymorphic among American Negroes, with almost $10 \%$ being $\mathrm{CpAB}$. Although $\mathrm{CpC}$ is much less frequent, four independent occurrences have been detected-one in Connecticut, two in Michigan, and one in South Carolina. The gene frequencies calculated from these data are also presented in Table III. Although the $C p^{A}$ gene does occur in Caucasians, its frequency is very low. The expected phenotypic distribution among Negroes, assuming Hardy-Weinberg equilibrium, is shown in parentheses. The observed values closely fit the expectation.

\section{Immunochemical and Enzymatic Properties}

Figure 5 shows an immunoelectrophoretic result obtained with sera of the five $\mathrm{Cp}$ phenotypes reacted against a specific rabbit anticeruloplasmin serum. Note that the positions of the precipitin bands are consistent with those expected if the $\mathrm{CpA}, \mathrm{CpB}$, and $\mathrm{CpC}$ components have mobilities on agar electrophoresis similar to their mobilities on starch gel. When a similar slide was incubated in the ceruloplasmin staining solution, the precipitin bands developed the typical intense brown color of oxidized $o$-dianisidine. These results demonstrate two points. First, the variant oxidase components on starch (and agar) gel electrophoresis are antigenically similar or identical to the common $\mathrm{CpB}$ form, indicating that these variant components are structurally altered ceruloplasmins. Second, the similar mobilities of the A and C electrophoretic forms on both agar and starch gel indicate that these variants probably involve charge differences, rather than different polymeric forms, since there is no molecular size effect upon mobility in agar electrophoresis.

In Fig. 3 it may be seen rather readily that in the $\mathrm{CpAB}, \mathrm{CpAC}$, and $\mathrm{CpBC}$ phenotypes the two oxidase bands are not of equal intensity. The faster component in each case is always more intense than the slower. This difference in intensity could be due to different amounts of protein or to different specific activities of the different electrophoretic forms. The immunoelectrophoretic result on CpAC (Fig. 5) suggests a lesser amount of the $\mathrm{C}$ component than the $\mathrm{A}$, so this may involve a difference in amount of protein. However, further investigation will be necessary to clarify this point. It has also been found that the relative staining intensities are the same when $p$-phenylenediamine, $N, N^{\prime}$-dimethyl-p-phenylenediamine, or benzidine are used as substrates. (Optimal staining is obtained with these substrates when the $p \mathbf{H}$ of the incubation mixture is 4.7 instead of 5.5.) Thus, the effect, whatever its basis, is the same for all of the commonly used ceruloplasmin substrates. These observations 


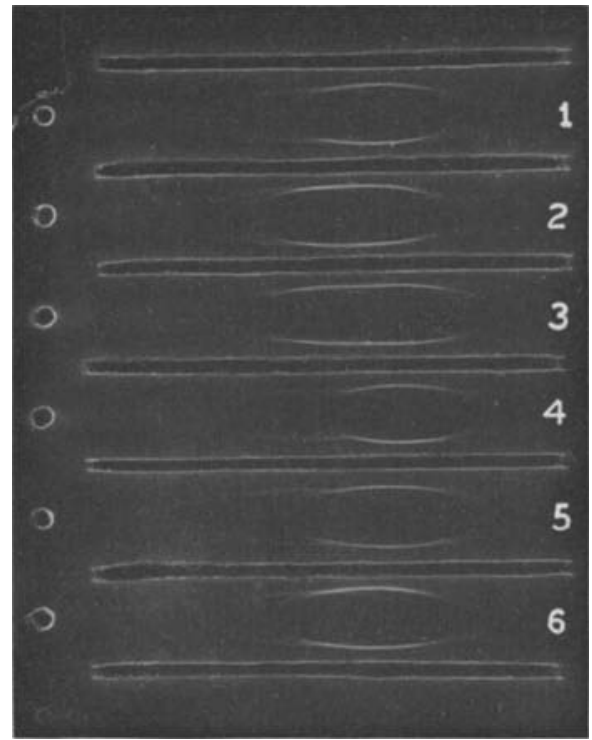

Fig. 5. Immunoelectrophoretic patterns of the five ceruloplasnin phenotypes. The anode was at the right. The more intense precipitin bands are ceruloplasmins. The more cathodal precipitin band in each pattern is due to antibody to a nonceruloplasmin protein present in the rabbit anticeruloplasmin used in the antiserum troughs. The $\mathrm{Cp}$ types of the sera were: (1) $\mathrm{CpB}$; (2) $\mathrm{CpBC}$; (3) $\mathrm{CpAC}$; (4) $\mathrm{CpA}$; (5) $\mathrm{CpAB}$; (6) $\mathrm{CpB}$. 

also demonstrate that the ceruloplasmin polymorphism is detectable with these more widely used substrates. However, it should be pointed out that, at least in our hands, the different electrophoretic components are most sharply resolved when $o$-dianisidine is used as the substrate.

\section{Relationship to $\mathrm{Cp} 1 \mathrm{~F}$}

The first genetically determined electrophoretic variant of ceruloplasmin was reported by Martin et al. (1961) and was called Cp 1F. This fast variant, found in a family of Irish descent, was compared in our laboratory and in the laboratory of Dr. Martin with our $\mathrm{CpA}$ and $\mathrm{CpAB}$ phenotypes, and it is clearly different. First, it is characterized by a single electrophoretic species apparently transmitted as a dominant (our tests of four members of the $\mathrm{Cp} 1 \mathrm{~F}$ family confirm the findings of Martin et al.), whereas the A variant is codominantly inherited. Second, the single fast band of $\mathrm{Cp} 1 \mathrm{~F}$ is slightly slower electrophoretically than the fast band of a Negro CpA or $\mathrm{CpAB}$. Thus, the $\mathrm{Cp} 1 \mathrm{~F}$ and $\mathrm{CpA}$ electrophoretic forms appear to be genetically, and probably structurally, distinct.

\section{DISCUSSION}

Our results show the existence of three distinct electrophoretic forms of serum ceruloplasmin which are under genetic control and which constitute a genetic polymorphism in American Negroes. The genetic data are consistent with control of the fast and intermediate forms, $\mathrm{CpA}$ and $\mathrm{CpB}$, by autosomal codominant alleles. $\mathrm{CpC}$ is probably controlled by an allele at the same locus, but critical genetic data are lacking. Biochemical evidence suggests that ceruloplasmin is composed of at least two unlike kinds of subunits (Poillon and Bearn, 1966), so structural variation under the control of another ceruloplasmin locus is a definite possibility. Final proof of allelism of the $\mathrm{CpC}$ type with $\mathrm{A}$ and $\mathrm{B}$ must await further data. Further segregation data on $\mathrm{CpA}$ and $\mathrm{CpB}$ will also be helpful.

More ceruloplasmin variation remains to be defined. At least two additional variant forms have been observed, each in a single family. One apparently has mobility intermediate between A and B, the other is intermediate between B and C. These types require further investigation and will be the subject of a later report. However, they do raise the problem of nomenclature and notation. If additional variants are detected, how should they be designated? It is suggested that the $\mathrm{CpA}$, $\mathrm{CpB}$, and $\mathrm{CpC}$ notation introduced here be utilized for these relatively frequent forms. If additional genetic types are defined, they should be given distinctive geographical names. If additional ceruloplasmin loci are defined, the one defined herein controlling the $\mathrm{CpA}-\mathrm{CpB}$ difference might be designated $C p-1$, with alleles $C p-I^{B}$ and $C p-1^{A}$, and new loci could be called $C p-2, C p-3$, etc., or $C p-\alpha, C p-\beta$, etc., could be used to indicate specific subunits of the molecule.

Because of its frequency in American Negroes, $C p^{A}$ should be a useful marker for genetic studies in Negro groups. It remains to be determined how widely this gene may be distributed in other populations. It is infrequent in some American Indian 
and Oriental groups. However, more extensive surveys are required and are in progress for some populations.

It has been suggested (Bearn, 1966) that the fundamental defect in Wilson's disease may be a reduction in synthesis of ceruloplasmin. This reduced synthesis might be due to mutation at a structural locus or at a regulatory locus. The discovery of structural variants of ceruloplasmin offers the opportunity to test whether the gene causing this disease is a mutant allele at the $C p$ structural locus. We have done electrophoresis on serum from one patient with Wilson's disease and find, as have others, that the ceruloplasmin mobility is indistinguishable from that of the common form, $\mathrm{CpB}$. This, of course, does not exclude structural alteration in the ceruloplasmin of such patients. If families with Wilson's disease can be found among Negroes, the $C p^{A}$ marker provides the means to test for allelism. It is to be hoped that any Negro families in which the condition is detected will be examined for this possibility.

\section{ACKNOWLEDGMENTS}

We wish to thank Mr. John McCormick for excellent technical assistance, Dr. Henry Gershowitz for blood typing the T family, Dr. George Martin for generously supplying sera from the Cp $1 F$ family, Dr. Curtis Hames for the Georgia twin specimens, and Dr. Raymond Dern for the Chicago twin specimens. We are also grateful to Dr. John Morrison who obtained some of the specimens from Connecticut. The Tecumseh serum samples were obtained from a project supported by U.S. Public Health Service Program Project Grant H-6378.

\section{REFERENCES}

Bearn, A. (1966). Wilson's disease. In The Metabolic Basis of Inherited Disease, 2nd ed. Edited by J. B. Stanbury, J. B. Wyngaarden and D. S. Fredrickson. McGraw-Hill, New York, pp. 761-779.

Brewer, G. J., Gall, J. C., Honeyman, M., Gershowitz, H., Shreffler, D. C., Dern, R. J., and Hames, G. (1967). Inheritance of quantitative expression of the X-linked gene, glucose-6-phosphate dehydrogenase deficiency, in heterozygous Negro females-A twin study. Biochem. Genet. 1: 25 .

Broman, L. (1958). Separation and characterization of two ceruloplasmins from human serum. Nature 182: 1655.

Epstein, F. (1960). An epidemiological study in a total community: The Tecumseh project. Univ. Mich. Med. Bull. 26: 307.

Hirschfeld, J. (1959). Individual precipitation patterns of normal rabbit sera. Acta Path. Microbiol. Scand. 46: 229.

Holmberg, C. G., and Laurell, C. B. (1948). Investigations in serum copper. II. Isolation of the copper-containing protein and a description of some of its properties. Acta Chem. Scand. 2: 550.

Imlah, P. (1964). Inherited variants in serum ceruloplasmins of the pig. Nature 203: 658 .

Laurell, C. B. (1960). Metal-binding plasma proteins and cation transport. In The Plasma Proteins. Edited by F. W. Putnam. Academic Press, New York, pp. 349-378.

Martin, G., McAlister, R., Pelter, W., and Benditt, E. P. (1961). Heterogeneity of ceruloplasmin. Proc. 2nd Intern. Congr. Human Genet. 2: 752.

Morell, A. G., and Scheinberg, I. H. (1960). Heterogeneity of human ceruloplasmin. Science 131: 930.

Owen, J. A., and Smith, H. (1961). Detection of ceruloplasmin after zone electrophoresis. Clin. Chim. Acta 6: 441 .

Poillon, W. N., and Bearn, A. G. (1966). The molecular structure of human ceruloplasmin. Evidence for subunits. Biochim. Biophys. Acta 127: 407. 
Poulik, M. D. (1963). Heterogeneity and structural subunits of human ceruloplasmin. In Protides of Biological Fluids, Volume 10. Edited by H. Peeters, pp. 170-182.

Poulik, M. D., and Bearn, A. G. (1962). Heterogeneity of ceruloplasmin. Clin. Chim. Acta 7: 374.

Richterich, R., Temperli, A., and Aebi, H. (1962). Die Heterogeneität des Ceruloplasmins. Biochim. Biophys. Acta 56: 240.

Shreffler, D. C., Brewer, G. J., Gall, J. C., and Honeyman, M. S. (1966). Genetic polymorphism in human serum ceruloplasmin. 3rd Intern. Congr. Human Genet., Abstr. of Contrib. Papers. pp. 91-92.

Smithies, O. (1955). Zone electrophoresis in starch gels: Group variations in the serum proteins of normal human adults. Biochem. $J .61: 629$. 